\title{
Food Safety and Technological Implications of Food Traceability Systems
}

\author{
Hailiang Zhang, Xudong Sun, and Yande Liu \\ East China Jiaotong University, School of Mechatronics Engineering, 330013, China
}

\begin{abstract}
Food safety has become an important food quality attribute.Both food industry and authorities need to be able to trace back and to authenticate food products and raw materials used for food production to comply with legislation and to meet the food safety and food quality requirements. Traceability is increasingly becoming a necessary task in the food industry which is mainly driven by recent food crises and the consequent demands for transparency in the food chain. This is leading to the development of traceability concepts and technologies adapted to different food industry needs. The content of this paper include several aspects such as overseas food traceability system present conditions and development, food traceability system present conditions, problems and prospect in China, put forward the main measures of pushing on food traceability system of china.
\end{abstract}

Keywords: food traceability, quality, safety, technology.

\section{Introduction}

The demand for food traceability has significantly expanded in the last few years all over the world with increasing incidence of food-related safety hazards and scares such as footh-and-mouth disease, mad cow disease, microbial contamination of fresh produce, dioxin in poultry which greatly decline consumer confidence on food safety. There can be found several definitions for traceability, such as "the ability to follow the movement of a food through specified stages of production, processing and distribution"(Codex Alimentarius,2004), "the ability to trace the history, application or location of that which is under consideration" or "when considering a product, traceability can be related to the origin of materials and parts, the processing history, the distribution and location of the product after delivery"(International Standardization Organization (ISO)). The EU Regulation 178/2002 describes it as "the ability to trace and follow a food, feed, food-producing animal or substance intended to be, or expected to be incorporated into a food or feed, through all stages of production, processing and distribution".(E.Abad,2009) The term "food traceability" can be traced back to 1986, the year that the first case of mad-cow disease (Bovine Spongiform Encephalopathy, BSE) was reported in the UK. Four years later, the government of UK started a committee to survey the cause and origins of BSE, using the traceability system of cattle production, which is the embryonic form of the current food traceability system. Food traceability has placed responsibilities on producers, processors, 
caterers and other handlers in the supply chain to ensure food safety because foods are mostly composed of more than one ingredient and have often been composed of a series of processes. Raw material producers, ingredients/packaging suppliers, distributors, storage operators, retailers, points of sale, shops, and transporters are all relative partners of the food traceability system. Within the food industry, traceability implies the ability to trace and follow feed, food, and food producing through all stages of production, processing, and distribution. As a result, making a complete traceability system will need enormous resources and effort. Traceability is essential, particularly with raw materials, to establish that control procedures have been applied and are effective. There are good examples of where traceability has had a specific approach, e.g. beef labelling and genetically modified materials.(M.F Stringer,2007) Traceability systems can be considered as a bridge between producers and consumers, since the details of where the products come from and how they are marketed is available for those who are concerned.

\section{Technological Implications of Food Traceability Systems}

Food traceability system is highly knowledge-intensive and increasingly informationdriven. Technological innovations are necessary to reduce transaction costs and facilitate the production of top quality,safe and traceable products to meet consumer demands. Technological innovations are needed for product identification,process and environmental characterization, information capture, analysis, storage and transmission. These technologies include hardware (such as measuring equipment, identification tags and labels) and software (computer programmes and information systems).

\subsection{Food Product Identification Technology}

A major character of the food traceability system is the ability to trace-back the history and the physical location of the food products. To achieve these, accurate labeling is essential. The simplest technology to achieve this is to attach a tag to the surface of the food package and to transfer that data on the tag to the bar code of the food product. (Fig.1)The use of computers and other information technologies have spurred the development of electronic identification (EID) systems, which include electronic tags with chips and scanners for reading, storing and transmitting the data to PCs for analysis and long-term storage. An important attribute of tags is that the materials must be resistant to rough handling and bad weather. Advancements in material science have led the development of tags that are resistant to tear which can withstand harsh environmental conditions.Innovations in geospatial science and technology such as radio frequency technology and mobile tracking devices have the potential for collecting and transmitting data from tags to distant locations for storage and analysis.

\subsection{Quality and Safety Measurement Technology}

The success of traceability is to meet the expectations of the consumer and other stakeholders, the ability to ascertain the location of the food product for effective recall in the event of food quality or safety breach. This requires accurate information 


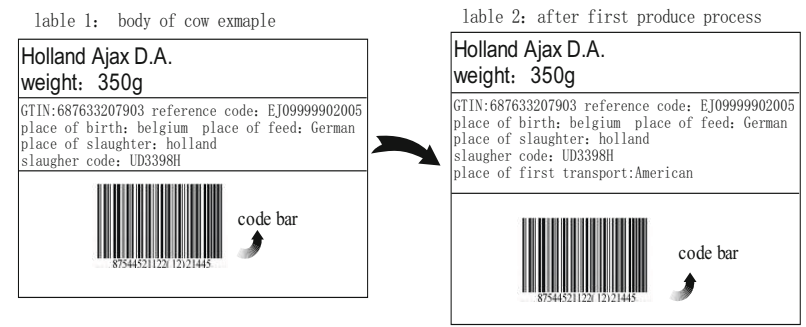

Fig. 1. Bar code of the food product

on the maturity and quality attributes and safety status of the product, which must be measured and analyzed using appropriate instrument and procedures. Product features such as size, firmness, soluble solids, acidity, flavour, etc, are some of the physical, mechanical and chemical properties that may require measurement. Nondestructive tests based on force sensing, infrared and magnetic resonance imaging can also be used to measure firmness and other internal quality attributes (Linus U. Opara,2003).

\subsection{Genetic Analysis Technology}

The need to preserve the identity of food product and the demand for genetic traceability have led to the development of procedures and measurement devices for the analysis of the genetic constitutions and contamination of foods and other biological products(Giese, J.H. 2001).

\subsection{Environmental Monitoring Technology}

Environmental conditions such as data of temperature and relative humidity collecting, atmospheric composition of the air including pollutants and so on which impact on the quality stability and safety of food products. Instrumented environmental recording devices for monitoring these parameters are available (Linus U. Opara,2003) .environmental monitoring process is shown in Fig.2.

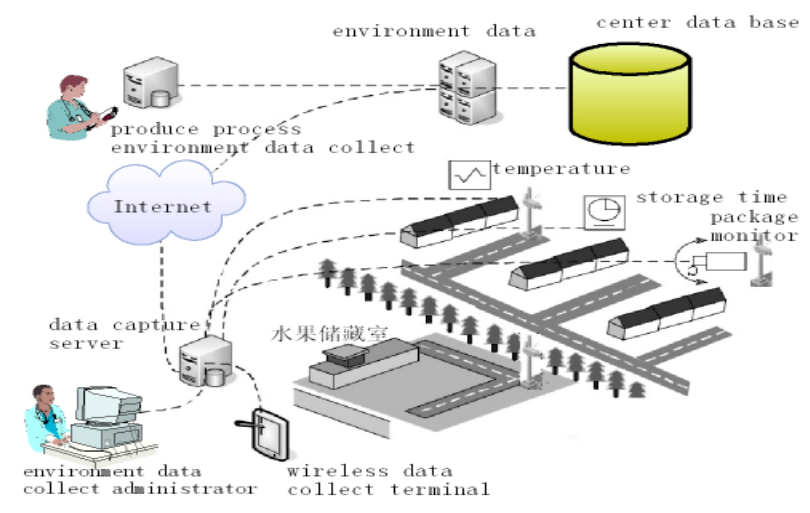

Fig. 2. Environmental monitoring process 


\subsection{Evelopments in Geospatial Science and Technology}

The integration of geographic information systems (GIS), remote sensing (RS) and global positioning systems (GPS) offers considerable opportunity for the derivation of data related to the food products. These technologies enable data to be remotely collected on a farm, which can be processed, transmitted and presented as product attributes. With respect to food traceability, a vital feature of these technologies is the possibility to map the geospatial variability of selected attributes such as yield, product quality (Bossler, J.D. 2001).

\subsection{Web and Database Technology for Food Traceability System}

Web and database technology relies on the application of appropriate computer system, and which links the food traceability to a central database at the company, national or international level.(Fig.3) Food traceability systems require lots of data uploading to be saved as digital files. The growth in the use of personal computers, with immense processing power, and the continued development of the Internet provides an appropriate environment.The increasing speed and capability of the required communication hardware together with falling prices also contribute to the viability of such a system. Modern personal computers provide a simple means of connecting to the outside world, using software and hardware which are provided with the machine.The system makes use of Internet technology to implement a worldwide solution.It is the physical connectivity of the Internet, as well as the communication protocol (TCP/IP) that is used. The food traceability system can be quickly deployed anywhere in the world. This can be communicated directly to the database server.This process is automated and transparent to the user. After being verified by officially qualified institutions, agricultural food products are labeled with a traceable combination of numbers, just like IDs for foods. Purchasers who purchase goods with these labels can trust the products are officially guaranteed to be of safe and high quality. Terminals set at retail markets are the communication port of producers and consumers. Once the traceable label is scanned on the machine, the detailed traceable information will be showed on the terminal screen.

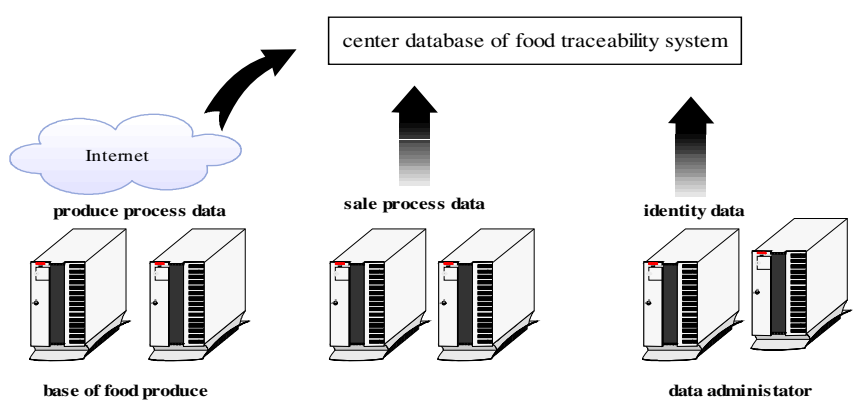

Fig. 3. Center database structure of food traceability system 


\subsection{RFID Technology}

Tags, which contain an integrated circuit chip and antenna, are integrated into objects such that these objects can be identified and their label information can be read. Radio frequency identification involves detecting and identifying a tagged object via radio waves transmitting data from tags to a reader (Jung Lyu Jr.,2009). One of the greatest challenges of implementing food traceability system under certain circumstance lies in the fact that products distribution has a global covering, thus it becomes difficult to precisely trace goods movement throughout the distribution chain. There is a solution that could eliminate these difficulties - an automate gathering of data named radiofrequency identification RFID). Moreover, the RFID tag can store much more information than the linear bar code, and the information can be updated. Sometimes, solutions can be thought in order to combine bar code technology, RFID and vocal recognition, to create a flexible infrastructure which would optimally use the advantages of each technology. (Goodrum, McLaren, \& Durfee, 2006; Kwon \& Choi, 2008). RFID technology allows the storing of information about all the products that have circulated in a certain container. This type of traceability is very useful for retailers, who can easily locate where to find a certain product, for a rapid delivery. With the help of the RFID tags, a supplier of fresh products (fruit and vegetables, for example) can trace where the goods have been delivered in order to accelerate the payment, or a retailer can be sure that the products are on shelves in the order they were stocked.

\section{Overseas Food Traceability System Present Conditions and Development}

As knowledge and economic grow, the people in developed countries are more concerned about quality and safety of food. Food traceability system is considered as a risk management tool for food safety and is widespread in developed countries such as Japan, the U.S., Canada and many countries in the European Union. Food traceability systems can provide clear, correct sources and marketing routes of food products. With an integrated food traceability system, the government can recall the products immediately and limit the possible loss. In December 2003, the United States developed the statutes of tracking food safety,"Farm Security and Rural Investment Act" requires country of origin labeling for many kinds of food, including perishable agricultural commodities, which required all enterprises involved in food transportation, distribution and import recording their trade information for tracking and tracing back. In addition, the United States also plans to include 70 percent of the cattle in the NAIS (National Animal Identity System) project at the end of 2009. The European Union adopted mandatory traceability actions in food industry since 1st January 2005, Regulation No. 178/2002 establishes that food business operators must label adequately food, in order to facilitate the traceability(Official Journal of the European Union,2002). The Marche Region (Italy) project called SiTRA, aiming to provide food chain stakeholders with a Web platform managing traceability for the main regional food products. Consumers can identify the SiTRA traced products by means a Regional Brand (QM Quality guaranteed by Marche) embedded in the 
product label, reporting the traceability code to access the Web for traceability information of the product. SITRA platform is currently tracing 8 large food chains (fresh milk, bread, pasta, fresh fish, olive oil, wine, pigs and cattle) all over the Region. In June 2002, the Canadian federal government established an ambitious goal that, before 2008, the country would achieve tracing back 80 percent of agricultural products to its source, supporting the "Brand Canada strategy", of which a mandatory identification system for cattle and beef on July 1, 2002 came into operation. Japan was the first country to introduce a food traceability system in Asia. Due to the occurrence of a series of food safety events, the Japanese government raised food traceability system promotion to the list of important administration policies of Prime Minister Koizumi and expected to accomplish 50\% implementation of food traceability in 2007 and $100 \%$ by the year 2010.Since 2001, the Japanese government has been promoting the development and use of food traceability systems, and the integration of traceability systems with agricultural risk management systems in order to improve food safety amongst food operators such as producers (farmers), retailers, and manufacturers (Nanseki and Yokoyama, 2008). The supply chain networks for the food industry are reacting both to global trends and to the changes brought about by the continued expansion and ever-deeper integration of the European Union. Ferrer and Findlay (2003) hold the opinion that the drive to unity is strong, but the diversity of competitive practices, labour laws, and regulations across Europe different countries and regions is rich. The supply chain winners will be those who can continue to create new opportunities through the implementation of optimised networks and the development of collaborative partnerships across their extended enterprises. (Ingrid Hunt, 2005).

\section{Food Traceability System Present Conditions in China}

\subsection{Present Conditions}

It is highly necessary for China to establish traceability systems. For concerning about both domestic food safety and international trade, since 2000 China has been adopting lots of measures and programs to introduce, extend, encourage and even mandate traceability system in food supply chain. In legislation, there are a few specific laws or regulations concerning food safety but little referring traceability before 2001 . There have been numerous food contamination events and animal diseases like avianinfluenza, foot-and-mouth disease, bad duck eggs and event of milk in recent years, causing extensive panic among the populace and tremendous losses to the farmers of China. Regarding on substantial advantages such as reducing marketing costs, ensuring product integrity, increasing consumer confidence, China is now developing and implementing food traceability programs throughout (Ministry of Commence of China, 2006). Provide visibility of China's food safety and quality systems to consumers, importers and governments of world, as well as to domestic businesses and consumers. Enhance the user's confidence on the safety of materials, raw materials and products from China. In order to ensure food safety, Beijing had established a specialized food safety traceability system for the 2008 Olympics, in order to monitor food quality from the origin of production to each stage of processing, packaging, 
transportation, distribution till ultimate consumption. The Beijing Administration for Industry and Commerce (BAIC) and Beijing Food Safety Supervision Office (BFSSO) already founded Beijing Food Safety Traceability System (henceforth BFSTS) based on Capital Food Safety Monitoring System (CFSMS) under the network environment of BAIC. BFSTS consists of one first-level platform and four individual sub-systems. The first-level platform is that Beijing Data Centre for food safety traceability, which is responsible for information collection, analysis, evaluation, tracing, early-alarming. The four sub-systems includes fruit and vegetable, animal products, prepackaged food and Olympic food traceability sub-system. One survey in city markets and rural markets performed in 2006 by Ministry of Commence of China showed that $53.7 \%$ of city markets, $32 \%$ of supermarkets, $80.4 \%$ of wholesale markets of agricultural products, $70.7 \%$ of retail markets introduced the above initial measures to foster traceability (Ministry of Commence of China, 2006). More than half of frozen food had already been able to be traced back to origin in 2008. In April 2004, the State Food and Drug Administration and other departments chose meat industry as a pilot industry, started meat and meat products traceability institution construction and system implementation (General Administration of Quality Supervision. 2002). The main tasks include: developing suitable technical standards and Management norms, publishing guidelines for implementing traceability system including "Meat products tracking and tracing Guide" and "Fresh product tracking and tracing Guide". In June 2004, Administration of national barcode management promoting investigated on vegetable products traceability and started an application project on two vegetable production bases located in Shouguang and Luocheng respectively in Shandong province. The project was successful in food quality control in the origin and enforcing standards of market access, product identification and recall. Integrated with electronic auctions and E-commerce, this project established a traceability system for pollution-free vegetables. Shanghai Livestock Bureau legislated to build digital archives for pigs, cattle, sheep, and the residents can now get access to the egg production information through internet. In August 2008, Beijing had already enforced a food traceability system along the full supply chain for the food supplied for Olympic games to secure food quality and safety. According to the law of People's Republic of China on food products' safe quality issued in 2006, all agricultural enterprises must set up production recording that should be authentic and be kept for at least 2 years; otherwise, the transgressor will be penalized not more than 5000 RMB. In addition, individual producers are also encouraged to keep recording within their own production. Such actions are considered as the rudiments of food traceability system in China. On June 26 of 2006, Ministry of Agriculture of China (MOA) promulgated the regulation on animal labeling and their feeding documents establishment in farms (No. 67 Act).In this act, the most key points are as follows: animals such as swine, cattle and sheep/goats in the farms must be gained unique identity code around the China, and it shall be labeled with a special tag embodying a unique code before moved from its region of origin. The feeding enterprises must establish their feeding information documents to record inputs mainly used, such as feeds, feed additives and veterinary drugs as treatment. Traceability on food-produced animals will be started in case of any of the following issues: (a) Some labeling are not in accord with livestock and products from 
themselves; (b) Livestock and their products have been infected or contaminated by some diseases and virus; (c) There is no quarantine certificate authorized by the accredited institution; (d) Some veterinary drugs and other venomous substance have been used, which are forbidden in terms of related regulations; (e) when serious animal health events occurred; and (f) other situations in which traceability should be applied.

\subsection{Problems and Measure of Pushing on Food Traceability System of China}

Promoting food traceability systems among consumers should focus on obtaining recognition from consumers. Being unfamiliar with this new concept in china, the public may consider "traceability" only as a commercial term, which makes no difference whether the products are traceable or not. Since most consumers don't understand the principle and value of food traceability systems, the Chinese government should endeavor to educate the public on the concept of food safety and possible food contamination routes. Once the public recognize that the food traceability system is a possible solution which can prevent certain problems and ensure their health, they will be interested in traceable food products and be willing to purchase the traceable agricultural products at a higher price. Recent theoretical literatures provide some useful information relevant to analyzing different consumers' increasing concerns about food quality and safety knowledge and the effect on food choices. Some studies about consumers show knowledge about food safety tends to increase with age, level of education, and experience in food preparation. These research findings are useful to assist in research of Chinese consumers' perception toward quality and safety of safe products (Wang Feng, Zhang Jian, 2009). The basis of the traceability system is the detailed data recorded by the producers. In the early days of promotion in China, most of the farmers didn't consider the traceability system as a constructive policy but rather a complicated and inconvenient one. From their viewpoint, the consumers would not care about the traceable records; the policy was considered just a waste of effort and time. Besides, some older farmers are not educated as well as the young; so even the ordinary paper records are huge obstacles for them, not to mention electronic documents. For companies, compliance to legislation is recognized as the major driving force towards introducing a quality supervision and traceability system. Value added to products through increased consumer confidence may be another important reason. The government should start to educate the producers about the advantages of implementing food traceability systems, popularizing the concept of food safety, making them believe that this could be a wonderful resource with full cooperation and could lead to a more profitable career. The endorsement from consumer to food traceability system is the biggest strength of promotion. Food safety and quality, rather than price, is considered the most important factor affecting food product purchasing decisions of Chinese consumers (Zhang, 2002). Once the consumers agree and favor the traceable products, the rise in profits will bring confidence to the producers. Through mutual trust established via food traceability systems, the benefits of both the producers and the consumers can be ensured. Therefore, food traceability systems 
can be considered as an investment which gives farmers profitable and stable business, and safe food for the public, leading to a promising future for sustainable agriculture.

\section{Conclusion}

The emergence of food traceability system is the result of developments in improving food quality and safety management. Farmers, processors and handlers, and food policy experts need to be aware of future developments in this area to assist them in implementing food traceability systems for their enterprises. The methods for data capture, data exchange, data storage and the integration of the food traceable supply chain are essential for the success of food traceability system. The traceability system of food products, including fish, poultry and meat products, means that the information of a product, from producing and processing to marketing, is recorded and can be traced, "from farm to fork". If all the food products are implanted with traceability, the consumer can not only query detailed information about the food but also secure themselves from impairment by checking suspicious process in the food supply chain through the food traceability system.

\section{References}

1. Codex Alimentarius, Codex Alimentarius Commission. FAO/WHO (2004)

2. Abad, E., Palacio, F., Nuin, M.: RFID smart tag for traceability and cold chain monitoring of foods: Demonstration in an intercontinental fresh fish logistic chain. Journal of Food Engineering, 394-399 (2009)

3. Stringer, M.F., Hall, M.N.: A generic model of the integrated food supply chain to aid the investigation of food safety breakdowns. Food Control 18, 755-765 (2007)

4. US Federal Register: Farm Security and Rural Investment Act of 2002, vol. 68(210), October 30 (2003)

5. Official Journal of the European Communities: Regulation (EC) No 178/2002 Of The European Parliament And Of The Council of 28 January 2002, article 18 (2002)

6. RFID Position Statement of Consumer Privacy and Civil Liberties Organizations, Privacy Rights Learing house (November 30, 2003)

7. Bossler, J.D. (ed.): Manual of geospatial science and technology, p. 664. Taylor \& Francis Group plc., UK (2001)

8. Opara, L.U.: Traceability in agriculture and food supply chain: A review of basic concepts, technological implications, and future prospects. Food, Agriculture \& Environment 1(1), 101-106 (2003)

9. Giese, J.H.: Lab exhibits promote traceability and safety. Food Technology 55(8), 100, 102-104 (2001)

10. Ferrer, J., Findlay, C.: European supply chain management characteristics and challenges. Ascet achieving supply chain excellence through technology (2003), http: / / www . ascet. com (accessed 11/09/2003)

11. Hunt, I., Wall, B.: Applying the concepts of extended products and extended enterprises to support the activities of dynamic supply networks in the agri-food industry. Journal of Food Engineering 70(2005), 393-402 (2005) 
12. Lyu Jr., J., Chang, S.-Y., Chen, T.-L.: Integrating RFID with quality assurance system Framework and applications. Expert Systems with Applications 36, 10877-10882 (2009)

13. Goodrum, P.M., McLaren, M.A., Durfee, A.: The application of active radio frequency identification technology for tool tracking on construction job sites. Automation in Construction 15, 292-302 (2006)

14. Feng, W., Jian, Z.: Consumers' perception toward quality and safety of fishery products, Beijing, China. Food Control 20, 918-922 (2009)

15. Zhang, X.: Consumption trends and habits for fishery products in China. In: ASEM Aqua Challenge Workshop (2002) 